This is an electronic reprint of the original article. This reprint may differ from the original in pagination and typographic detail.

Author(s): Paloviita, Ari; Järvelä, Marja

Title: $\quad$ Climate Change Adaptation and Food Supply Chain Management : An overview

Year: $\quad 2015$

Version:

Please cite the original version:

Paloviita, A., \& Järvelä, M. (2015). Climate Change Adaptation and Food Supply Chain Management : An overview. In A. Paloviita, \& M. Järvelä (Eds.), Climate Change Adaptation and Food Supply Chain Management (pp. 1-14). Routledge. Routledge Advances in Climate Change Research.

All material supplied via JYX is protected by copyright and other intellectual property rights, and duplication or sale of all or part of any of the repository collections is not permitted, except that material may be duplicated by you for your research use or educational purposes in electronic or print form. You must obtain permission for any other use. Electronic or print copies may not be offered, whether for sale or otherwise to anyone who is not an authorised user. 


\section{Chapter 1 - Climate Change Adaptation and Food Supply Chain Management: An Overview}

Ari Paloviital and Marja Järvelä²

${ }^{1}$ University of Jyväskylä, Department of Social Sciences and Philosophy

P.O. Box 35, 40014 University of Jyväskylä, Finland; ari.paloviita@jyu.fi

${ }^{2}$ University of Jyväskylä, Department of Social Sciences and Philosophy

P.O. Box 35, 40014 University of Jyväskylä, Finland; marja.jarvela@jyu.fi

\section{Introduction}

In the future, climate adaptation will become an inescapable task for the management of the food supply chain both globally and locally. The gradual warming of the world's mean temperature and the increased frequency of extreme weather is expected to have a major impact on food supply chain performance and food security (IPCC 2014). Obviously, food supply chain performance and food security will be at risk and vulnerable due to multiple other factors as well, thus it is an issue of high importance and high complexity - from a societal perspective - to find practical measures of adaptation for the world's food chains. Adaptation is also important for more conventional reasons because agriculture and the food sector form an important part of the world's economy, for instance in the EU economy they provide 15 million jobs, $8.3 \%$ of the EU's total employment, and $4.4 \%$ of the EU's GDP (Moussis 2013).

In trying to attain a resilient food supply, global and local transformations are needed in both socioeconomic and socio-ecological systems. When defining adaptation to climate change as a social action, we usually refer to processes and actions that help systems, such as household, organisation, community, region, country, in order to better manage and adjust to changing conditions, stresses, hazards, risks or opportunities (Smit and Wandel 2006). In this book we consider some of the main actors usually responsible for designing and operating a food system so that it takes on a more sustainable and/or resilient pattern of action. By considering food systems in a comprehensive yet operative manner, we focus on how food chain dynamics function as a whole instead of studying parts in isolation from one another. 
In more concrete terms, food is material we eat. But it is not just that; the discerning end-user may have strong cultural values related to not only the volume but also to the quality of the end product. Furthermore the end-user may also have demands concerning how the food was produced and its origin. For example, at the upstream end of the food chain, a farmer looking for an alternative concept to his current, not-so-profitable pig farm, may wish to start a more environmentally friendly alternative such as raising wild boars. How can he know that the entire food chain will adjust accordingly?

To start a wild boar farm instead of continuing with a conventional pig farm, the farmer first needs to reform his feed provision and build suitable facilities for grazing. Second, he needs to know who would be the main customers for the meat. This may involve the external food industry and the requirement to make contracts with retail, restaurants or other customers. Finally, the consumer, or a consumer group, needs to accept the replacement of at least some part of his/her conventional pork with boar meat. This path may appear a quite simple and viable model. However, we live in a complex world with global driving forces where hardly any actor is free to act in an entirely autonomous manner. Instead, we make choices that are not just the influence of morals, taste and market dynamics but which are also affected by rules and regulations in every phase of the food chain. This makes the topic of food chain management adapting to climate change challenging but also stimulating.

\section{Beyond mitigation, beyond vulnerable agriculture, beyond the business case}

A food supply chain is an economic subsystem of a broader socio-ecological system. By adapting the definition of supply chain made by Christopher (1998), the food supply chain can be defined as a network of organizations that are involved, through upstream linkages to farms and downstream linkages to consumers, in the different processes and activities that produce value in the form of food products and food services for consumers. The food supply chain concept is driven by business management scientists in the fields of logistics, physical distribution, operations management, marketing and supply chain management. Hence, food supply chain management has traditionally focused on developing economic value within the food supply chain network through value-adding activities and efficiency. 
However, a food supply chain is not an island. It is a subsystem of a broader food system, which is a concept originally promoted by rural sociologists in the 1990s (Ingram 2011). Similarly to the food supply chain, a food system includes activities from production to consumption, i.e. a chain of activities from the field to the table - from farm to fork. The key difference between a food supply chain and a food system is that the latter includes the interactions between and within the biogeophysical and human environments and also the societal outcomes of the activities (Ericksen 2008). Conceptually, environmental and social values are addressed on a par with economic values in a food system.

Sustainable food supply chain management has been introduced as a management concept in order to address environmental and social issues in food supply chain management. According to Seuring and Müller (2008), sustainable supply chain management "is the management of material, information and capital flows as well as cooperation among companies while integrating goals from all three dimensions of sustainable development, i.e. economic, environmental and social, which are derived from customer and stakeholder requirements". In a sustainable food supply chain, management issues such as food safety (not to be confused with food security), quality assurance, tracking and tracing practices, the origin of the food products, the inputs used during production, the labour standards, the treatment of animals and the environmental impact of production are important (Beske et al. 2014). However, the typical outcome of corporate sustainability activities in a food supply chain is to create economic value (see Figge and Hahn 2012). Social and environmental issues are addressed as far as there is a "business case". Moreover, sustainable supply chain management has been traditionally more concerned about the impacts of food supply chain activities on the environment and society rather than the impacts of global environmental and social changes on the business environment.

According to Dyllick and Hockerts (2002) there are three types of capital - economic, natural and social - relevant to economic, environmental and social sustainability. These types of capital are non-subsitutable, for example, higher wages cannot subsitute for the loss of clean water. In addition, the deterioration of natural and social capital is irreversible and the loss of biodiversity and the impacts of climate change are definite. Hence, the loss of cultural diversity is equally definite. Taking all that into account, it is clear that it is necessary to move beyond the business case in food supply chain management because environmental and social outcomes should not be subordinate to financial outcomes. Rather, corporate sustainability strategies should create environmental and 
social value alongside economic value (Figge and Hahn 2012). Identifying the societal case and the natural case for food supply chain management is a critical step towards creating a sustainable food system.

Climate change adaptation is an example of a societal case for food supply chain management. Specifically, it is a social learning process in which the intermediate goal should be to empower all actors in a food system so that they learn to learn how to adapt to climate change (FAO 2014). Also, in management literature, the organisational learning model is the most highly developed attempt to understand how, why and when organisations will adapt to climate change (Nitkin et al. 2009, 26). As an issue demanding a societal perspective, climate change adaptation is firmly related to major global issues such as hunger, food security, food waste, water supply and energy supply. The world's food systems are extremely vulnerable to climate change - whether through extreme weather conditions, gradual changes in climate or a combination of both. At the same time, climate change adaptation is a local approach associated with local livelihood, rural entrepreneurship and community development. Global food supply chains need to address both global changes in the world's food systems and the value of localisation. The majority of business discourse on climate change adaptation is concerned with risk mitigation and takes an indirect approach to climate change adaptation, tending to frame adaptation in terms of vulnerability and adaptive capacity, risk and opportunity (Nitkin et al. 2009, 17). The indirect aspects of climate change adaptation in business literature are regulatory, financial, physical, litigation, reputational and competitive risks (Nitkin et al. 2009, 18). Accordingly, climate change will affect food supply chains in varying ways, depending on the complexity of the supply chain and on the degree of inter-connectedness and dependency of and on other industries (Beermann 2011).

There are barriers towards effective climate change adaptation in food supply chains. First, the institutionalization of climate change mitigation is still an ongoing process. One goal of climate change mitigation is to reduce greenhouse gas emissions, especially carbon dioxide emissions. However, this aim has not achieved a consensus at inter-governmental level. In the light of recent IPCC reports, it must be admitted that climate change mitigation policy has, to a large extent, failed. Consequently, climate change impacts will affect economies and societies in fundamental ways but, because governments have not succeeded in climate change mitigation at the global level, climate change adaptation must take place at local, regional and national levels. However, adaptation is still being confused with mitigation (Nitkin et al. 2009, 19). Hence, a shift in focus from the inside-out impacts of a food system, i.e. emissions from food system activities, to outside-in impacts, i.e. the 
physical and regulatory climate change impacts on food system activities, is required (Porter and Reinhardt 2007). Second, the majority of the literature dealing with climate change adpatation in food systems has focused on agricultural activities. This rather obvious, but limited view of climate change adaptation in the food system has neglected other critical activities beyond the farm gate, such as the food industry; processing and manufacturing activities; the logistical system and infrastructure supporting food supply chains; wholesale and retail; and consumption and postconsumption activities. As Eakin $(2010,78)$ puts it, a shift in focus is needed from concentrating on vulnerable agriculture to focusing on food system vulnerability. Third, food supply chain management is solely based on the business case and consequently biased towards financial performance. It has been generally suggested that companies should shift their focus beyond the business case and financial performance in order to deal with relevant societal issues (Vaara and Durend 2012). Hence, a shift in focus from the food supply chain to the overall food system is required. It must be also noted that climate change adaptation is embedded into the social and cultural worlds and is highly influenced by political processes, which means that depoliticising climate change adpatation and treating it as separate from societal processes runs the risk of exacerbating inequities and vulnerability (Mosberk and Eriksen 2014).

The link between climate change adaptation strategies and resilience thinking has been generally acknowledged in academia (e.g. Beermann 2011). Resilience is a useful concept in understanding the importance of adaptive capacity and coping strategies in order to decrease the vulnerability of the food system. Resilience can be examined at the farm level, community level, food company level, food supply chain level and household level. According to Ericksen et al. (2010, 73) managing food systems for resilience is an approach focusing on the dynamic processes of change that produce feedback into the food systems. A sustainable food system approach, in turn, can be ensured by integrating intra- and intergenerational justice and by deliberately taking the planetary boundaries into consideration (Gold and Heikkurinen 2013).

\section{Vulnerable spaces and resourceful places - local responses}

While sustainable development has been declared and confirmed as a universal policy target, globalisation has increased pressure on local economies and food systems. The pressure on agriculture and SME processing and manufacturing in particular has been varied, including heavy price competiton from global markets, imported, novel food items and lower standards in farm employment in low-income countries. In view of the global competition, the mainstream policy 
answer has been further modernisation, ameliorated technological efficiency and increased competitiveness in agriculture, food processing and food manufacturing. Consequently, it is important to remember that all political attempts - whether local or global - that aim at climate change adaptation also need to fit with the main trends of current policies.

From the point of view of the traditional local diversity of food production, modernisation has reduced that diversity as a result of the increased standardisation of food supply, economics of scale, longer delivery distances and related vulnerabilities in the food supply chain. However, another implication of this trend is that the producers and end-users in a food supply chain are socially and spatially increasingly distant from one another, even if they buy and sell at either end of the chain. Therefore this mega-trend of modernisation is being realised in an ever more fierce struggle between local traditional farming and small-scale processing at one end and the "macdonaldization" of food at the other end. Recently, however, a critical cultural factor has entered the scene; firstly, it manifested as critical views on overly standardised bulk production and, secondly, as an increasing demand for alternatives, such as quality food and organic production, and finally as active local food movements. Potentially, all these alternatives increase the diversity of the food chain provided that alternative production is feasible for farmers and SMEs, and that all the players in a food chain can adapt their strategies towards these alternatives. Hence, social structures, the role of locality, local micro-business networks and business network relationships that contain farmers and SMEs should be acknowledged by food chain researchers as critical aspects of sustainable performance (Bourlakis et al. 2014) and climate change adaptation.

Even if, much of this experimenting on the local "re-rooting" and the "re-routing" of the food supply has followed dynamics other than purposive adaptation to climate change, it may also serve either directly as mitigation or indirectly to mitigation by contributing to local climate adaptation mechanisms. In general, it is important to recognise that these re-localisations generate new arenas to interact in for food chain actors who were isolated from each other by modernisation. According to many case studies (including some presented in this volume), re-rooted local communication and co-operative action for alternative food concepts can increase social capital and community resilience. However, these emerging trends to adjust food chains so that they become sustainable and can adapt to climate change are remarkably embedded in particular localities and regions. Thus, the prerequisites for these to emerge and prosper are evidently strongly related to both sociocultural and socio-economic assets that can be mobilised (Marsden and Smith 2005). Natural resources and spaces need to be translated into places enabling food chain initiatives that have real 
meaning to those who will take the initiative to build more resilient food chains (e.g. Battaglini et al. 2009).

Local assets for food chain management are obviously highly different in terms of social and economic resources according to space and place. In the long-term European tradition, the spatial structures of food production have been formed by seeking an effective balance between three different types of land use, namely ager, saltus and silva (e.g. Pinto-Corrreia and Vos 2004). Each of these types of land use needs their own adaptation dynamics, yet also a mutual balance based on both material and cultural basics is required. For example, some localities are more suitable for large scale ager type cultivation while others would profit most from saltus type grazing areas with more natural vegetation, or even from sustainable forestry relying on silva type of localities. Under the circumstances of major uncertainty - set up by the local impacts of future climate change, it is of great importance to consider how we understand the human-natural world metabolism in the long-term through both agriculture and the world's food chains.

When considering our capacity to act and alleviate the threat of climate change, the above exploration of the food chain, food system and food chain management reveals major issues that must be tackled. These issues have their origin in the increasing complexity of our food chains and the broader food systems. Some constellations of these problems seem to lead to paradoxes that are difficult to unlock. Perhaps it is limiting to propose only one generalisable solution for any of these problems and it is more desirable to look for at least a double solution that would benefit from functioning parallel dynamics. Having more than one option might better match the landscape of the increasing uncertainties that are prevailing, even though the volume of climate change research is multiplying. Flexibility and rapidly applicable alternatives are clearly needed in circumstances where both natural and societal shocks are likely to emerge. An obvious limitation in the existing business-case dominated supply chain management literature on sustainability performance and climate change adaptation is the exclusion of farms and SMEs (Bourlakis et al. 2014).

\section{Farm size and family farm}

One of the intriguing issues that seem to come up constantly when trying to figure out the next steps to enhance resilience in food production is the social mode of farming. This issue is often linked to the recommendable scale of on farm production, because building resilience is connected to the capacity for affordable investment in new equipement and facilities. In many countries, family 
farms still produce the majority of food. Simultaneously, however, farms are adjusting their activities more and more so that they fit into patterns of modern private entrepreneurship. Many articles including some in this book highlight the transformations required on family farms in order to adapt to the shocks typical of global markets and ultimately of climate change (Darnhofer 2010; Wilson 2008). Again it seems that there is no single solution for everyone in this adaptation. In the midst of a globally competitive economy, the traditional mode of the family farm seems to survive or even thrive depending on its flexibility and capacity to modify production lines and farming practices, even if the true challenges brought to the fore by climate change remain distant and quite fuzzy to farmers and their close business partners.

The other major issue of social resilience connected to the social mode of production appears to be the problem of the size of the farms (e.g. Bindi and Olesen 2011). Currently, mainstream modernisation is trying to attain efficiency though economies of scale. At the same time there are many indications that social resilience on farms can be more likely reached through measures that increase the "economy of scope", that is the variety of product and production, rather than by means of economies of scale (Marsden and Smith 2005). Nevertheless, looking at the issue globally, the operative farm size seems to have risen with the level of economic development, especially in the 20th Century. However, Eastwood et al. (2010) argue that there are marked exceptions to this trend, such as the high prevalence of small farms in parts of North-Western Europe and diminishing farm size in South Asia, despite economic growth. Therefore it seems that increasing farm size is not necessarily the most effective measure with which to build food chains with a high adaptive capacity for the future. There is also the empirical evidence that small firms in the food supply chains are the top performers in terms of sustainability performance measures due to their flexibility and responsiveness (Bourlakis et al. 2014).

Besides, relatively small scale and family farm management seem to fit together. The fact that the family remains the main source of farm labour seems to bring some advantages in building good and resilient farming practices. Family management, however, can also appear as an impediment to radical transformation or major investment. One interesting aspect of this complexity of the driving forces involved in the adaptation is the issue of the effect of generational shift on working practices. It seems that major transformations are often connected to successful generational turnover. 


\section{Actors in the food chains - complexities to be dealt with}

One way to understand the present modernisation of the world's various food systems is to focus on the capacity building of the actors in these processes (Marsden and Smith 2005). Then it is possible to say that these actors are not only present in farm management, but also in the entire food chain. Consequently, the actors' capacities and their mutual cooperation can be the decisive assets for enhancing resilience in all of its main aspects. Furthermore, the issue of scale is very relevant to the resilience of the entire food chain and its operators. Many researchers have found that in local communities there might be a major discrepancy between the sizes of the actors which have to cooperate with one another, leading to inequalities in power and influence. For example, local food industries may be small-scale and numerous. However, a few well-organised, large companies might simultaneously have the decisive, controlling power in the organising of the market. Hence, it is not at all insignificant as to who will be the main business partners for farmers in such a situation.

Since the second half of 20th Century, technology has been a major driving force behind food production and all related services. On farms, the rapid mechanisation of farm practices has had a major impact on both investment and the demand for labour. In particular, productivity per labour unit has increased dramatically in high consumption societies leading to a major outflow of the rural population. Now, the prevailing socio-technical systems, based on high financial investment, may have, at least in a short run, a decisive impact on the capacities available to be mobilised for the adaption of food chains to climate change. A modern food chain has high technological requirements, not only for production, but also for transport and storing. All these assets may be extremely vulnerable to escalating climate change, thus obliging responsible actors to build professional capacities accordingly.

Developing technological systems for resilient food chain requires multiple methods for measuring the impacts and for surveying both direct climate change impacts and the efficiency of the measures established to mitigate and adapt to climate change. Indeed, many sets of indicators have been built and experimented with recently. Yet, the question remains, how accurate can these indicators be when we are trying to facilitate appropriate and politically feasible societal practices. In fact, much of the current measurement of food chain resilience still has the status of work in progress, even if some of it has been strongly institutionalised by, e.g. FAO, EU and many nation states. On the other hand, it is widely recognised that farms and SMEs seldom have the time, resources or information required for mitigation and adaptation measurement, which also means that farms and SMEs do not have a clear understanding of their own performance with regards to mitigation and adaptation 
(Bourlakis et al. 2014). Several articles in this volume tackle the problem of accurate measurement within food chain management, while some of them explore relatively new targets of systematic measurement, such as food waste.

The modernisation of agriculture and food chains has resulted in a paradoxical situation for the traditional producer and SMEs; although, the key position of farm and SME food production is recognised as an indispensable part of a food chain, the farmer/entrepreneur often struggles with the multiple pressures of value acquisition because their share of the total food chain income tends to be shrinking - even below that of a living wage in some places. Moreover, large firms in a chain may start dominating others in it by demanding the others conform to their needs regarding what can be delivered and how. For example, Arend and Wisner $(2005,427)$ stated that supply chain management "is not a good fit for SMEs on several performance measures" and that "conflict exists over how supply chain management affects small and medium-sized companies". This tendency has led to complex circumstances that can be challenging with regard to providing alternative models for the (re)organising of food chains through new modes of entrepreneurship and interactive practices, where even consumers are allowed to have a bigger say in sending a strong message upstream towards farms - either directly or through the intermediate actors in a food chain.

Capacity building can happen individually or collectively. When considering the many pressures of modernisation, not just climate change, many of the actors have already done their best to solve adaptation issues on their own. And even if it is clear that climate change adaptation still requires the further enhancing of individual capacities or the capacities of basic units, such as family farms, SMEs, etc., the most important challenge is to find pathways for more community-based and socially interactive patterns of production and consumption. This volume includes several articles that highlight several such options for building a more resilient food chain based on the various actors' civic initiatives and mutual effort. However, a constant issue is: how autonomously can these actors successfully operate with their new ideas? This issue is connected to the debate on the need for institutional support, which may be organised in a number of ways. Yet, in building a resilient food chain, the core of the organising dynamics often lies more on the local than the national level. Moreover, sectorial measures that may lean on the long-term administrative tradition may not be the most effective ones for building new capacities into a food chain, so that it would become resilient.

\section{New challenges for food chain research}


The nexus between climate change adaptation and food supply chain management has appeared as an emerging area of research and practice in which there is much work to be done. The impetus to assess climate change vulnerabilities and to increase resilience in agriculture is clear, but climate change adaptation in the food supply chain and in the overall food system is a very new field. This book aims to fill this gap and will thereby complement the existing literature. There are specific chapters dedicated to each major phase of the food supply chain: input production (e.g. plant breeders in Chapter 4), primary production (e.g. farms in part III), food processing and manufacturing (e.g. food processing firms in Chapters 7 and 16), retail (e.g. wholesalers and retailers in Chapter 16), consumption (e.g. culinary cultures in Chapter 14) and post-consumption (e.g. food waste in Chapter 15). As the food supply chain is affected by the socio-economic, sociopolitical and socio-cultural environment, an interdisciplinary approach will be required.

This book aims to move the whole agenda of climate change adaptation forward. It acknowledges the importance of climate change adaptation in agriculture, but extends the system boundaries in climate change adaptation to the entire food supply chain. It also acknowledges the importance of the business case in the food supply chains, but extends the boundaries in climate change adaptation to the overall food system. Hence, the relevance of climate change adaptation is examined as a business case and a societal case, which are presented through various perspectives in this book. The impacts of climate change will vary according to farm, company, location in the supply chain and geographical location. Vulnerability to climate change in a particular region, company or supply chain will depend on their exposure and sensitivity to weather extremes, climate variability and gradual changes in climate as well as to their adaptive capacity. The extent and the form of climate change adaptation will also vary as the identified risks and vulnerabilities alter. It should be noted, however, that this book does not aim to make a clear distinction between climate change adaptation and climate change mitigation, as adaptation is generally "interpreted in a wide variety of ways by a wide variety of actors and is a highly contextual process dependent on variables such as sector, region and size of firm" (Nitkin et al. 2009, 19). For example, climate change influences societal and cultural processes, but it is also intensified by societal and cultural processes, which means that successful adaptation approaches must include mitigation efforts in the long run (Beermann 2011). According to Adger et al. (2009, 3) adpatation and mitigation efforts "are invariably intertwined and feed into each other" at the local level. 


\section{Structure of this book}

This chapter has introduced the focus of the book - climate change adaptation and food supply chain management. The subsequent chapters of this book include four core sections, with 15 chapters that address various aspects of and approaches to food supply chain vulnerability and resilience. The sections are here presented in thematic order.

The first section introduces the broader themes of food security, vulnerability and resilience. The second chapter by Jokinen, Mononen and Sairinen deals with the vulnerabilities of the global food system by clarifying the links between food security and climate change. The third chapter by Tapiola and Paloviita focuses on the resilience of the Finnish food system by employing general resilience indicators. The fourth chapter by Paavola, Himanen, Kahiluoto and Miettinen gives an insight into the discussions between plant breeders and researchers on the response diversity of crop cultivars, which is one of the food systems' attributes for resilience. Hence, Part I of the book starts with a global food system focus and then concentrates on national food systems and finally elaborates on actor-level interactions.

The first two chapters of Part II of the book highlight the wider European context, whereas two other chapters are rooted in the Finnish context. Chapters 5 to 8 of the second section present concrete approaches to methodologies and strategies for assessing and coping with vulnerabilities and exploiting entrepreneurial opportunities. The fifth chapter by Juhola and Neset deals with assessment of vulnerability and the adaptive capacity of food systems. The development of assessment methodologies is discussed based on a broad overview of the literature on vulnerability to climate change. Chapter 6 by Brunori and Silvasti presents climate-related vulnerabilities and opportunities in the food systems of Italy and Finland from the perspective of food security. In Chapter 7, Puupponen examines the linkages between climate change, vulnerability and local adaptation strategies from the perspective of food enterprises in Finland. The authors of Chapter 8, Hartikainen, Pulkkinen, Katajajuuri and Peltonen-Sainio, have collaborated with the Finnish food industry in order to develop a methodology for assessing the carbon footprints of different foods. They focus on communication with consumers in the food supply chain.

Part III of the book is dedicated to farm-level adaptation and farm resilience, which is the cornerstone of the entire food supply chain. Concepts such as good farming, territorialisation and 
the family farm are discussed in the context of climate change adaptation. The experiences of the third section are derived from the rural areas of Finland and Serbia. The effects of the cultural understanding of good farming on farm resilience are explored in Chapter 9 by Huttunen, Mela and Hildén, who examine how a farmer's understanding of farming practices relates to their ability to adapt to climate change. A case study on farm resilience in the Zlatibor region of Serbia is presented in Chapter 10 by Battaglini, Babovic and Bogdanov, who analyse how farm resilience could be conceptualised as an inner dimension of the process of territorialisation. In Chapter 11 Lehtonen, Liu and Purola evaluate the role of farm-level socio-economic characteristics in climate change adaptation with regard to mitigation targets in Northern Europe. Farm-level economic models consistent with utility maximisation and risk aversion are used in simulating the rational choices of different farm types. Another approach to farm-level vulnerabilities and farm resilience is outlined in Chapter 12 by Järvelä and Kortetmäki, who focus on farm livelihood and rural development, which can be seen as forming the core of farm resilience.

Part IV of the book integrates the perspectives of the different phases of the food supply chain: primary production, food industry, retail, consumption and post-consumption. Moreover, the final section deals with the key determinants and relationships in climate resilient food supply chains. In Chapter 13, Kahiluoto, Rimhanen, Kuisma and Mäkinen provide insights into management options for resilient North European dairy systems. Mäkelä and Niva, in Chapter 14, analyse what people can do with their everyday diet and eating habits in order to diminish the environmental impact of food consumption. They also examine what kind of changes people are ready for and how they understand the environmental aspects of food and eating. The authors suggest the concept of sustainable culinary cultures, which, as a joint effort, would require collective action. Chapter 15 by Silvennoinen, Katajajuuri, Hartikainen, Heikkilä and Reinikainen focuses on food waste and related climate impacts in the Finnish food chain. Finally, Paloviita formulates Chapter 16 by elaborating upstream and downstream relationships in the food supply chain from the perspective of food processing firms/manufacturers and food wholesalers/retailers. The importance of the value chain approach, partnerships with farmers and consumers as well as the need for organisational, cultural and behavioural changes are highlighted in order to redefine food supply chains for resilience.

A more sophisticated form of food supply chain management, one imbued with a social purpose, is required. Climate change adaptation requires the recognition of new and better ways to develop food products and services and serve food markets, but society's overall interests should also be served as well. Climate change adaptation is clearly a process of producing societal benefits far 
beyond simply producing economic benefits for a small part of the world's population. For business managers, this book aims to explicate the social and environmental issues required in order to move beyond the mere business case in climate change adaptation. Business involvement in climate change adaptation is important as companies have "skills, resources and management capability to lead social progress in ways that even the best-intentioned governmental and social organizations can rarely match" (Porter and Kramer 2011). For policy makers, this book aims to improve knowledge and understanding about the food supply chain approach. More specifically, it aims to present an approach in which the concept of the broader food system would be taken into consideration. This approach would be required since it includes activities that are being neglected in current climate adaptation policies because they are conducted beyond the farm gate. The role of governments in assisting with climate change adaptation is equally important because they construct regulations, can set social and cultural goals and set legal standards for actors in food supply chains. For academia, this book represents the examining of the relevance of the broader societal issues related to food systems, and it also asks for the themes discussed in this book to be made part of other research agendas.

\section{Acknowledgements}

This research was funded by Academy of Finland through the research project A-LA-CARTE (decision no 140870).

\section{References}

Adger N W Lorenzoni I O'Brien K L 2009 Adapting to climate change: Thresholds, values, governance Cambridge University Press New York

Arend R J and Wisner J D 2005 Small business and supply chain management: Is there a fit? Journal of Business Venturing 20, 403-436

Battaglini A Barbeau G Bindi M Badeck F 2009 European winegrowers' perceptions of climate change impact and options for adaptation Regional Environmental Change 9(2):61-73

Beermann, M 2011 Linking corporate climate adaptation strategies with resilience thinking Journal of Cleaner Production 19 836-842 
Beske P L and A Seuring S 2014 Sustainable supply chain management practices and dynamic capabilities in the food industry: A critical analysis of the literature International Journal of Production Economics 152 131-143

Bindi M Olesen J E 2011 The responses of agriculture in Europe to climate change Regional Environmental Change 11, 151-158

Bourlakis M, Maglaras G, Aktas E Gallear D and Fotopoulos C 2014 Firm size and sustainable performance in food supply chains: Insights from Greek SMEs International Journal of Production Economics 152 112-130

Christopher M 1998 Logistics and supply chain management Ritman Publishing London Darnhofer I 2010 Strategies of family farms to strengthen their resilience Environmental Policy and Governance 20(4) 212-222

Dyllick T Hockerts K 2002 Beyond the business case for corporate sustainability Business Strategy and the Environment 11(2) 130-141

Eakin H 2010 What is vulnerable? In Ingram J Ericksen P Liverman D eds Food Security and Global Environmental Change Earthscan, Oxon 67-77

Eastwood R Lipton M Newell A 2010 Farm size, In Handbook of Agricultural Economics, Burlington: Academic Press 3323-3375

Ericksen P 2008 Conceptualizing food systems for global environmental change research Global Environmental Change 18 234-245

Ericksen P Bohle H-G Stewart B 2010 Vulnerability and resilience of food systems In Ingram J Ericksen P Liverman D eds Food Security and Global Environmental Change Earthscan, Oxon 7886

FAO 2014 LACC Project (http://www.fao.org/climatechange/laccproject/47741/en/) Accessed 10 December 2014

Figge F and Hahn T 2012 Is green and profitable sustainable? Assesing the trade-off between economic and environmental aspects International Journal of Production Economics 140 92-102 
Gold S Heikkurinen P 2013 Corporate responsibility, supply chain management and strategy: In search of new perspectives for sustainable food production Journal of Global Responsibility 4(2) 276-291

IPCC 2014: Summary for policymakers in Field C B Barros V R Dokken D J Mach K J Mastrandrea M D Bilir T E Chatterjee M Ebi K L Estrada Y O Genova R C Girma B Kissel E S Levy A N MacCracken S Mastrandrea P R and White L L eds Climate change 2014: impacts, adaptation, and vulnerability. Part A: Global and sectoral aspects. Contribution of Working Group II to the Fifth assessment report of the Intergovernmental Panel on Climate Change Cambridge University Press, Cambridge

Marsden T Smith E 2005 Ecological entrepreneurship: sustainable development in local communities through quality food production and local branding Geoforum 36 (2005) 440-451

Mosberg M Eriksen S 2014 The politics of climate change adaptation: Taking stock of academic and practiotioner experiences. Conference summary report.

(http://www.nmbu.no/sites/default/files/pdfattachments/conference_summary_report.pdf) Accessed 16 December 2014.

Moussis N 2013 Access to European Union: Law, economics, policies Intersentia, Rixensart

Nitkin D Foster R and Medalye J 2009 Business adaptation to climate change: A systematic review of the litarature Network of Business Sustainability (http://nbs.net/wpcontent/uploads/NBS_Systematic-Review_Climate-Change.pdf) Accessed 18 June 2014

Pinto-Correia T Vos W 2004 Multifunctionality in Mediterranean landscapes - past and future In Jongman R ed The New Dimensions of the European Landscape Wageningen EU Frontis Series, Springer

Porter M E and Kramer M R 2011 Creating shared value Harvard Business Review 89 (1-2) 62-77 Porter M E and Reinhardt F L 2007 A strategic approach to climate Harward Business Review October 2007 22-26

Seuring S and Müller M 2008 From a literature review to a conceptual framework for sustainable supply chain management Journal of Cleaner Production 16(15) 1699-1710

Smit B Wandel J 2006 Adaptation, adaptive capacity and vulnerability Global Environmental Change 16 282-292 
Vaara E and Durand R 2012 How to connect strategy research with broader issues that matter? Strategic Organization 10 248-255

West J 2014 The long hedge: Preserving organizational value through climate change adaptation Greenleaf Publishing, Sheffield UK

Wilson G A 2008 From 'weak' to 'strong' multifunctionality: Conceptualising farm-level multifunctional transitional pathways Journal of Rural Studies 24 (2008) 367-383 